\title{
Production of $\mathrm{O}_{2}$ through dismutation of $\mathrm{H}_{2} \mathrm{O}_{2}$ during water ice desorption: a key to understanding comet $\mathrm{O}_{2}$ abundances
}

\author{
F. Dulieu ${ }^{1}$, M. Minissale ${ }^{1, \star}$, and D. Bockelée-Morvan ${ }^{2}$ \\ 1 LERMA, Université de Cergy Pontoise, Sorbonne Universités, UPMC Univ. Paris 6, PSL Research University, \\ Observatoire de Paris, UMR 8112 CNRS, 5 mail Gay Lussac, 95000 Cergy Pontoise, France \\ e-mail: Francois.Dulieu@obspm.fr \\ 2 LESIA, Observatoire de Paris, PSL Research University, CNRS, Sorbonne Universités, UPMC Univ. Paris 06, Univ. Paris-Diderot, \\ Sorbonne Paris Cité, 5 place Jules Janssen, 92195 Meudon, France
}

Received 7 March 2016 / Accepted 11 August 2016

\begin{abstract}
Context. Detection of molecular oxygen and prediction of its abundance have long been a challenge for astronomers. The low abundances observed in few interstellar sources are well above the predictions of current astrochemical models. During the Rosetta mission, an unexpectedly high abundance of $\mathrm{O}_{2}$ was discovered in the comet 67P/Churyumov-Gerasimenko's coma. A strong correlation between $\mathrm{O}_{2}$ and $\mathrm{H}_{2} \mathrm{O}$ productions is observed, whereas no such correlation is observed between $\mathrm{O}_{2}$ and either of $\mathrm{CO}$ or $\mathrm{N}_{2}$.

Aims. We suggest that the $\mathrm{O}_{2}$ molecule may be formed during the evaporation of water ice. We propose a possible reaction: the dismutation of $\mathrm{H}_{2} \mathrm{O}_{2}\left(2 \mathrm{H}_{2} \mathrm{O}_{2} \longrightarrow 2 \mathrm{H}_{2} \mathrm{O}+\mathrm{O}_{2}\right)$, a molecule which should be co-produced during the water ice mantle growth on dust grains. We aim to test this hypothesis under realistic experimental conditions.

Methods. We performed two sets of experiments. They consist of producing a mixture of $\mathrm{D}_{2} \mathrm{O}_{\text {and }} \mathrm{D}_{2} \mathrm{O}_{2}$ via the reaction of $\mathrm{O}_{2}$ and $\mathrm{D}$ on a surface held at $10 \mathrm{~K}$. The first set is made on a silicate substrate, and explores the limit of thin films, in order to prevent any complication due to trapping during the desorption. The second set is performed on a pre-deposited $\mathrm{H}_{2} \mathrm{O}$ ice substrate and mimics the desorption of mixed ice.

Results. In thin films, $\mathrm{O}_{2}$ is produced by the dismutation of $\mathrm{H}_{2} \mathrm{O}_{2}$, even at temperatures as low as $155 \mathrm{~K}$. Mixed with water, $\mathrm{H}_{2} \mathrm{O}_{2}$ desorbs after the water ice sublimation and even more desorption of $\mathrm{O}_{2}$ is observed.

Conclusions. $\mathrm{H}_{2} \mathrm{O}_{2}$, synthesised during the growth of interstellar ices (or by later processing), desorbs at the latest stage of the water sublimation and undergoes the dismutation reaction. Therefore an $\mathrm{O}_{2}$ release in the gas phase should occur at the end of the evaporation of ice mantles. Temperature gradients along the geometry of clouds, or interior of comets, should blend the different stages of the sublimation. Averaged along the whole process, a mean value of the $\mathrm{O}_{2} / \mathrm{H}_{2} \mathrm{O}$ ratio of a few percent in the gas phase seems plausible.
\end{abstract}

Key words. astrochemistry - methods: laboratory: molecular - comets: general

\section{Introduction}

The recent in-situ measurements of the Rosetta Orbiter Spectrometer for Ion and Neutral Analysis (ROSINA) mass spectrometer onboard Rosetta have unveiled very large $\mathrm{O}_{2} / \mathrm{H}_{2} \mathrm{O}$ ratios in the coma of comet $67 \mathrm{P} /$ Churyumov-Gerasimenko (Bieler et al. 2015). Values fluctuate in time and range from $1 \%$ to $10 \%$, with an average at $3.8 \pm 0.8 \%$. Rubin et al. (2015) determined a value of $3.7 \pm 1.7 \%$ for comet $1 \mathrm{P} /$ Halley, from a reanalysis of measurements performed with the Neutral Mass Spectrometer onboard Giotto. Therefore $\mathrm{O}_{2}$ seems to be a common component outgassing from comets.

These results contrast with the very low level of $\mathrm{O}_{2}$ previously measured in the interstellar medium (ISM; Larsson et al. 2007; Goldsmith et al. 2011; Liseau et al. 2012; Yildiz et al. 2013), and with the low upper limit observed in other galaxies (Kanekar \& Meier 2015). The different media show an $\mathrm{O}_{2}$ abundance generally lower than that predicted by models, even if significant progress in modelling has been made

^ Present address: Aix Marseille Université, CNRS, PIIM UMR 7345, 13397 Marseille; Centrale Marseille, Institut Fresnel UMR 7249, 13013 Marseille, France.
(Hincelin et al. 2011; Melnick \& Kaufman 2015). Abundances of $\mathrm{O}_{2}$ are also very low in planetary atmospheres (Hall et al. 1995; Johnson et al. 2006), although physical conditions and processes at play are very different from those in comet nuclei.

For comets and in some of interstellar regions the link of the $\mathrm{O}_{2}$ molecule with water desorption is well established (Goldsmith et al. 2011). However, $\mathrm{N}_{2}$ and $\mathrm{CO}$ behave differently from $\mathrm{O}_{2}$. A strong correlation between $\mathrm{O}_{2}$ and $\mathrm{H}_{2} \mathrm{O}$ number densities was observed in 67P's coma, whereas $\mathrm{CO}$ and $\mathrm{N}_{2}$ show much less of a correlation with $\mathrm{O}_{2}$ due to significant production from poorly illuminated regions (Bieler et al. 2015; Rubin et al. 2015). The binding energies of CO (volatile) and $\mathrm{H}_{2} \mathrm{O}$ are very different, and the absence of correlation between these two molecules is an unsurprising consequence of the different sublimation rates.

However, from an experimental point of view, $\mathrm{O}_{2}$ and $\mathrm{CO}$ (or $\mathrm{N}_{2}$ ) present similar desorption properties, including their trapping in pores of ice (Collings et al. 2004). Although Noble et al. (2015) have shown that they compete during the desorption phase, $\mathrm{CO}$ and $\mathrm{O}_{2}$ initially mixed in water should have globally the same desorption behaviour, and therefore the same correlation with water. This is, however, not what is observed. 


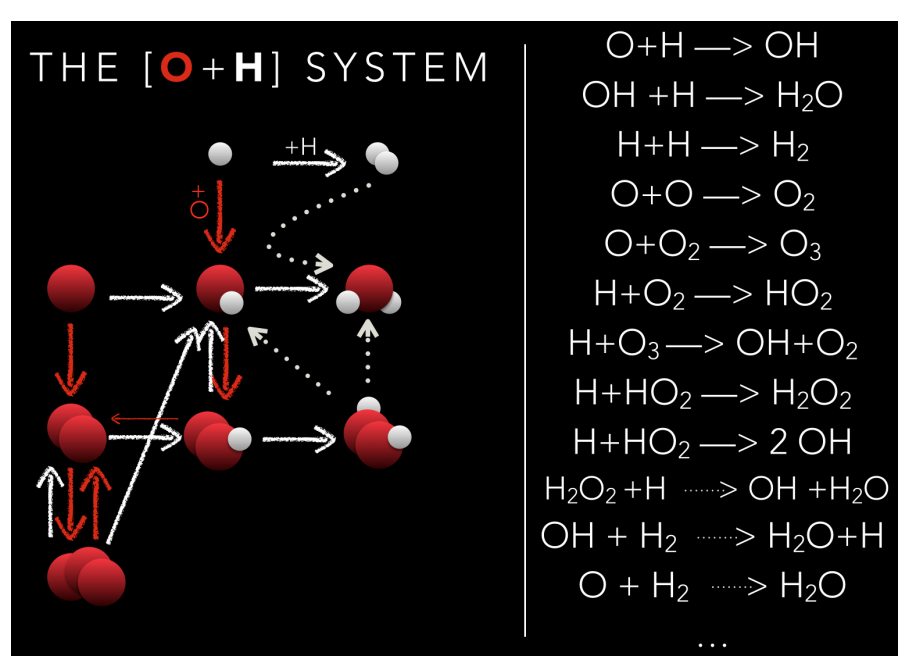

Fig. 1. $\mathrm{H}_{2} \mathrm{O}$ formation network in the solid phase. Red arrows: $\mathrm{O}$ addition. White arrows: $\mathrm{H}$ addition. Solid arrows: no (or not measurable) barrier to reaction. Dotted arrows: barrier to reaction. See also Lamberts et al. (2014).

Despite some trapping capability of porous ices, the desorption of most volatile species can happen prior to the ice desorption. This can be observed in experiments in which a low heating rate allowing an efficient diffusion of species into the ice is used (Noble et al. 2012). Therefore $\mathrm{O}_{2}, \mathrm{~N}_{2}$, and $\mathrm{CO}$ productions, led by their thermal history, should be correlated if they were present initially in the comets ice.

Oxygen and hydrogen are the most abundant reactive elements, and their chemistry generates the most abundant molecules in the Universe, both in the gas phase $\left(\mathrm{H}_{2}\right)$, and in the solid phase $\left(\mathrm{H}_{2} \mathrm{O}\right)$. These two molecules are thought to be catalyzed by the surface of cold $(10-100 \mathrm{~K})$ dust grains composed of silicates or carbonaceous materials. Recently, laboratory experiments have demonstrated that water is easily formed from $\mathrm{O}$ atoms (Dulieu et al. 2010; Jing et al. 2011), but also from $\mathrm{O}_{2}$ (Oba et al. 2009; Ioppolo et al. 2010; Chaabouni et al. 2012) or even $\mathrm{O}_{3}$ molecules (Mokrane et al. 2009; Romanzin et al. 2011) by addition of $\mathrm{H}$ atoms. The presence of $\mathrm{O}, \mathrm{O}_{2}$ and $\mathrm{O}_{3}$ at observable abundances on the surface of grains during ice growth is unlikely because of their high reactivity. Due to hydrogenation one expects an efficient transformation to $\mathrm{H}_{2} \mathrm{O}$. Water can also be produced by the reaction of $\mathrm{H}_{2}$ and $\mathrm{OH}$ (Oba et al. 2012). The network of solid-state reactions of water is displayed in Fig. 1. Water is easily formed in many ways, and since it is the most stable (i.e. non reactive) species, it is the natural endpoint of the $\mathrm{O}$ and $\mathrm{H}$ chemistry. However, we notice that especially when starting from $\mathrm{O}_{2}$ molecules, direct addition of two $\mathrm{H}$ atoms may lead to the formation of hydrogen peroxide. The molecule $\mathrm{H}_{2} \mathrm{O}_{2}$ is even the most abundant to be formed in the case of pre-deposited multilayers of $\mathrm{O}_{2}$ followed by $\mathrm{H}$ exposure (Miyauchi et al. 2008; Ioppolo et al. 2008). Once formed, $\mathrm{H}_{2} \mathrm{O}_{2}$ molecules can slowly evolve towards water, but the $\mathrm{H}_{2} \mathrm{O}_{2}+\mathrm{H}$ reaction has an activation barrier, and must proceed via quantum tunneling (Oba et al. 2014). It is unlikely that we find $\mathrm{O}_{2}$ mixed in the ice mantles because of its reactivity. In contrast, its main products $\mathrm{H}_{2} \mathrm{O}$ or $\mathrm{H}_{2} \mathrm{O}_{2}$ are very abundant in ice mantles and their ratio $\left(\mathrm{H}_{2} \mathrm{O}_{2} / \mathrm{H}_{2} \mathrm{O}\right)$ is determined by the degree of hydrogenation, or more exactly by the surface $\mathrm{H} / \mathrm{O}$ ratio during their formation. $\mathrm{H}_{2} \mathrm{O}_{2}$ can also be formed from energetic post processing of $\mathrm{H}_{2} \mathrm{O}$ (Westley et al. 1995), although the ratio $\mathrm{H}_{2} \mathrm{O} / \mathrm{H}_{2} \mathrm{O}_{2}$ is an equilibrium depending

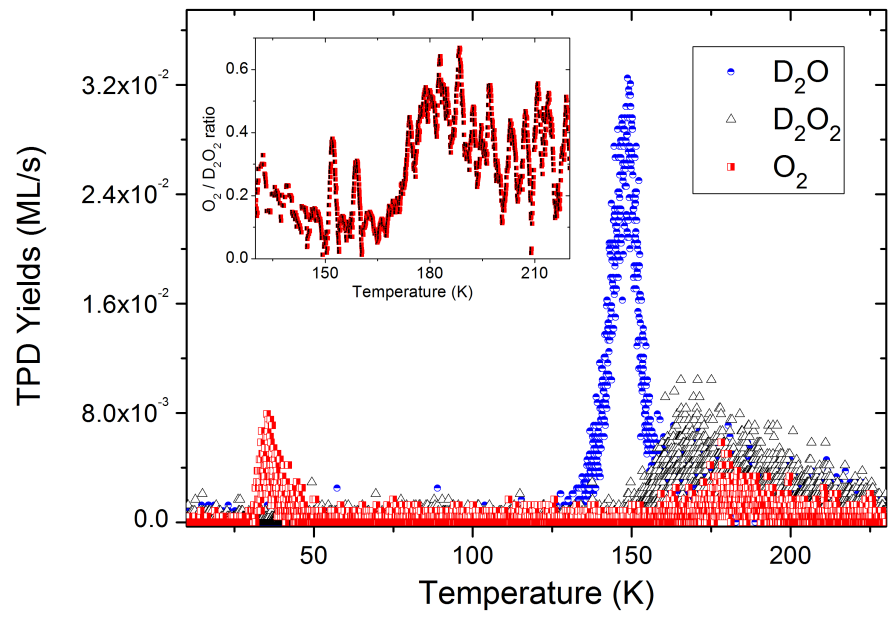

Fig. 2. TPD of $1 \mathrm{ML} \mathrm{O}_{2}$ reacting with $6 \mathrm{ML}$ of $\mathrm{D}$ atoms, on a silicate substrate held at $10 \mathrm{~K}$. Red squares: $\mathrm{O}_{2}$ signal; blue circles: $\mathrm{D}_{2} \mathrm{O}$ signal; black triangles: $\mathrm{D}_{2} \mathrm{O}_{2}$ signal. Inset: $\mathrm{O}_{2} / \mathrm{D}_{2} \mathrm{O}_{2}$ ratio.

on the irradiation conditions (Loeffler et al. 2006). Observational constraints put the upper limit of the $\mathrm{H}_{2} \mathrm{O}_{2} / \mathrm{H}_{2} \mathrm{O}$ ratio to be around 10\% (Smith et al. 2011) in ice mantles.

In this paper we investigate the possibility of the $\mathrm{O}_{2}$ molecule being produced during the desorption phase (i.e. the sublimation) of the water. This could happen because of either the dismutation or disproportionation of $\mathrm{H}_{2} \mathrm{O}_{2}$. Disproportionation/dismutation is a specific type of redox reaction in which a species is simultaneously reduced and oxidised to form two different products. In our context it is the following reaction:

$2 \mathrm{H}_{2} \mathrm{O}_{2} \longrightarrow 2 \mathrm{H}_{2} \mathrm{O}+\mathrm{O}_{2}$.

However, even though this reaction is well known at room temperature, or even bio-catalysed, it has yet to be tested in conditions relevant to astrophysical environments. Once the efficiency of this reaction is shown, we will discuss if this process can explain the large $\mathrm{O}_{2} / \mathrm{H}_{2} \mathrm{O}$ ratio observed in the coma of comet 67P/Churyumov-Gerasimenko.

\section{Experiments}

The experiments were performed using the FORMOLISM setup (Congiu et al. 2012). It is composed of a main UHV chamber, in which a temperature-controlled $(6-400 \mathrm{~K})$ sample holder is located. One atomic $\mathrm{D}$ beam and one $\mathrm{O}_{2}$ beam are aimed at the sample made of amorphous silicates for the first set of experiments. This sample was obtained by thermal evaporation of San Carlos olivine $\left(\mathrm{Mg}_{1.8} \mathrm{Fe}_{0.2} \mathrm{SiO}_{4}\right)$ onto a gold-coated substrate $(1 \mathrm{~cm}$ in diameter). The surface density of adsorption sites is about the same as that found on compact ice samples (Noble et al. 2012). Sample preparation and surface analysis are described extensively in Djouadi et al. (2005).

For the second set of experiments, the substrate is covered with an amorphous solid water ice (ASW) mantle with a thickness of about 25 monolayers. One monolayer (ML) corresponds to $10^{15} \mathrm{~mol} / \mathrm{cm}^{2}$. This ASW is compact because it has been formed at $110 \mathrm{~K}$, before being cooled to $10 \mathrm{~K}$, the temperature where both $\mathrm{O}_{2}$ and $\mathrm{D}$ are deposited. We use a $\mathrm{D}$ beam in order to distinguish the $\mathrm{D}_{2} \mathrm{O}$ and $\mathrm{D}_{2} \mathrm{O}_{2}$ formed by beam deposition from constituents of the substrate made of $\mathrm{H}_{2} \mathrm{O}$. Details of procedures can be found in Chaabouni et al. (2012). 
Figure 2 shows the thermally programmed desorption (TPD) of products made after exposure of $1 \mathrm{ML}$ of $\mathrm{O}_{2}$ with $6 \mathrm{ML}$ of $\mathrm{D}$ atoms, sent on the silicate substrate held at $10 \mathrm{~K}$. This proportion of reactants has been chosen to maximise the $\mathrm{D}_{2} \mathrm{O}_{2}$ production, which in this case leads to similar abundances of $\mathrm{D}_{2} \mathrm{O}$ and $\mathrm{D}_{2} \mathrm{O}_{2}$. The TPD technique consists of increasing the temperature of the substrate linearly, and monitoring the desorption profile of all products with a quadrupole mass spectrometer located in front of the sample. The heating ramp is $10 \mathrm{~K}$ per minute. The desorption of $\mathrm{O}_{2}$ occurs in two steps. The first one, at around $40 \mathrm{~K}$, is the $\mathrm{O}_{2}$ thermal desorption peak (unreacted $\mathrm{O}_{2}$ molecules). The second step of $\mathrm{O}_{2}$ desorption appears after the surface temperature has reached $175 \mathrm{~K}$. This part of the signal is not due to any contamination or cracking pattern, but is the demonstration that $\mathrm{O}_{2}$ is produced on the surface at this temperature. The water formed $\left(\mathrm{D}_{2} \mathrm{O}\right)$ is desorbing at around $150 \mathrm{~K}$, and but no codesorption of $\mathrm{O}_{2}$ is observed. The codesorption could have originated from the $\mathrm{O}_{2}$ present at $10 \mathrm{~K}$ and trapped by water, then freed during its desorption. The absence of codesorption demonstrates that the trapping mechanism is inefficient for such thin ices (less than a layer of $\mathrm{D}_{2} \mathrm{O}+\mathrm{D}_{2} \mathrm{O}_{2}$ formed). Furthermore there is a desorption tail of $\mathrm{D}_{2} \mathrm{O}$ at temperatures higher than $150 \mathrm{~K}$ which is not present if the same amount of $\mathrm{D}_{2} \mathrm{O}$ is simply deposited (and not formed). This signal is also due to the transformation of a product of the $\mathrm{O}_{2}+\mathrm{D}$ reaction, which occurs at high temperatures. $\mathrm{D}_{2} \mathrm{O}_{2}$ desorption starts once all the water has desorbed, because of its higher binding energy (Loeffler \& Baragiola 2011) to the silicate substrate. The $\mathrm{D}_{2} \mathrm{O} / \mathrm{D}_{2} \mathrm{O}_{2}$ ratio is close to unity in the $180-210 \mathrm{~K}$ region. The inset in Fig. 2 shows that above $180 \mathrm{~K} \mathrm{O}_{2} / \mathrm{D}_{2} \mathrm{O}_{2}$ is rather constant with a mean value of 0.4 . This is close to half of the $\mathrm{D}_{2} \mathrm{O} / \mathrm{D}_{2} \mathrm{O}_{2}$ ratio, taking into account the error bars.

We interpret the second desorption peaks of $\mathrm{O}_{2}$ and $\mathrm{D}_{2} \mathrm{O}$ in the temperature region of the $\mathrm{D}_{2} \mathrm{O}_{2}$ desorption as the signature of the dismutation of water peroxide into water and molecular oxygen. The stoichiometry $\left(2 \mathrm{H}_{2} \mathrm{O}\right.$ for $\left.1 \mathrm{O}_{2}\right)$ is also respected. The dismutation of water peroxide is a well known process occurring during the evaporation of $\mathrm{H}_{2} \mathrm{O}_{2}$ under atmospheric conditions or on metallic surfaces (Giguère \& Secco 1954). Our experiment shows that the dismutation can be efficient even at the temperature of ice sublimation under vacuum. Moreover, we point out that the dismutation rate is comparable with the desorption rate. We note that the dismutation efficiency increases with the temperature especially between 155 and $180 \mathrm{~K}$, before being stable. In these late conditions of desorption, the $\mathrm{D}_{2} \mathrm{O}_{2}$ dismutation is as probable as the desorption, in our sub-monolayers conditions.

The second set of experiments was performed on a predeposited $\mathrm{H}_{2} \mathrm{O}$ compact ASW of $25 \mathrm{ML}$ of thickness. Therefore, we expect a $\mathrm{H}_{2} \mathrm{O} / \mathrm{D}_{2} \mathrm{O}_{2}$ ratio of about $5 \%$ at the end of the exposure of reactants. This is more representative of the water formed in the ISM, although the results may become harder to interpret. Thanks to the use of $\mathrm{D}$, it is possible to disentangle between the molecules originating from the substrate and the molecules formed. Before the desorption phase, proton exchange is taking place (Scott Smith et al. 1997). Therefore, $\mathrm{D}_{2} \mathrm{O}_{2}$ is mainly detected as $\mathrm{HDO}_{2}$, and $\mathrm{D}_{2} \mathrm{O}$ is also detected as HDO. For sake of simplicity, we give no further details of how we treat the proton exchange in this article.

Figure 3 shows the desorption of mass $32\left(\mathrm{O}_{2}\right)$. Here again, there is an initial desorption at about $40 \mathrm{~K}$ (not represented), but no codesorption between 130 and $150 \mathrm{~K}$, and no volcano effect at the crystallization point at $145 \mathrm{~K}$. This is due to the fact that the substrate is compact and therefore the trapping mechanism is very reduced. However, there is a sudden release of $\mathrm{O}_{2}$

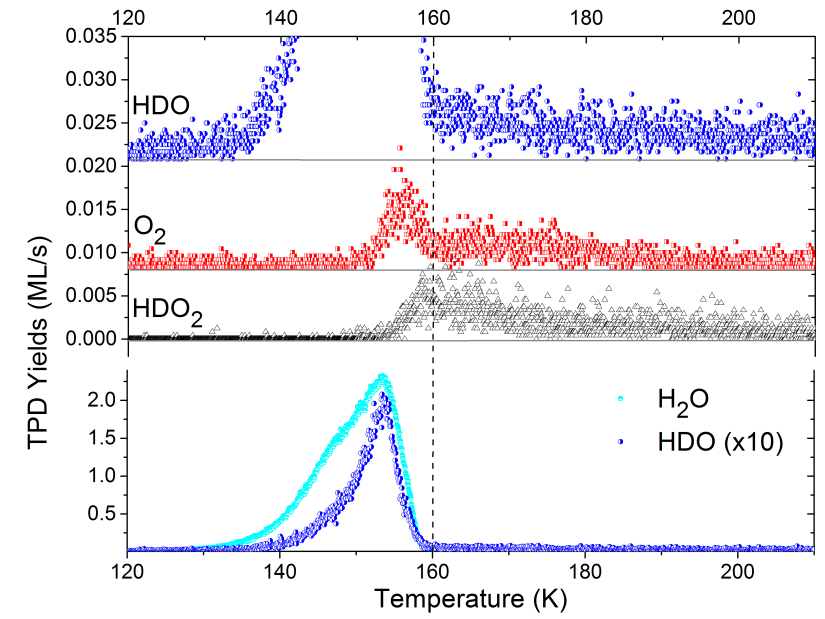

Fig. 3. TPD of $4 \mathrm{ML} \mathrm{O}_{2}$ reacting with $6 \mathrm{ML}$ of $\mathrm{D}$ atoms, on a silicate substrate held at $10 \mathrm{~K}$ pre-covered with $25 \mathrm{ML}$ of ASW. Top panel: $\mathrm{HDO}$ (blue circles), $\mathrm{O}_{2}$ (red squares), and $\mathrm{HDO}_{2}$ (black triangles). $\mathrm{HDO}$ and $\mathrm{O}_{2}$ curves are offset for clarity. Bottom panel: HDO (blue circles) and $\mathrm{H}_{2} \mathrm{O}$ (cyan circles) TPD signals. The HDO signal has been rescaled, in order to make the dynamics apparent.

at $155 \mathrm{~K}$, exactly when the water signal is starting to decrease. For multilayer samples, the decrease of TPD signals is due to the reduction of the surface density of adsorbates; in other words, it happens when the desorbing ice is thinner than a single layer. So the $155 \mathrm{~K}$ desorption of $\mathrm{O}_{2}$ is due to $\mathrm{O}_{2}$ locked (or formed) below the $\mathrm{H}_{2} \mathrm{O}$ ice. The sudden release of $\mathrm{O}_{2}$ at $155 \mathrm{~K}$ is not accompanied by a $\mathrm{D}_{2} \mathrm{O}_{2}$ signal, but is coincident with a high desorption rate of $\mathrm{D}_{2} \mathrm{O}$ which corresponds to just over twice the $\mathrm{O}_{2}$ rate. Here again the origin of $\mathrm{O}_{2}$ should be the dismutation reaction, because any trapped $\mathrm{O}_{2}$ should have desorbed earlier during the crystallisation of the water. However, we have to explain why it happens at the very end of the water sublimation, and not before. This is probably due to the fact that the substrate may catalyze the dismutation reaction, or due to the fact that the dismutation reaction requires high concentration of $\mathrm{H}_{2} \mathrm{O}_{2}$, both of which happen only when most of the water has left the surface.

The late desorption signal (above $160 \mathrm{~K}$ ) of $\mathrm{H}_{2} \mathrm{O}, \mathrm{O}_{2}$ and $\mathrm{D}_{2} \mathrm{O}_{2}$ is similar to that observed in a thin layer, except for the $\mathrm{H} / \mathrm{D}$ composition. Both $\mathrm{HDO}, \mathrm{O}_{2}$ and $\mathrm{HDO}_{2}$ are codesorbing with the same ratios as in the previous experiment. The absence of $\mathrm{D}_{2} \mathrm{O}$ signal at temperatures higher than $160 \mathrm{~K}$, is due to the prior proton exchange. A desorption tail of mass 19 (HDO) is observed instead between 160 and $200 \mathrm{~K}$ very similarly to the desorption of mass $20\left(\mathrm{D}_{2} \mathrm{O}\right)$ obtained in experiments made directly on silicates (Fig. 2), because there is no proton scrambling with the substrate in this case.

In the first set of experiments, the dismutation efficiency is about $50 \%$, whereas in the second experiment it is close to unity at $155 \mathrm{~K}$, the end of water sublimation.

\section{Discussion}

In astrophysical environments solid $\mathrm{H}_{2} \mathrm{O}$ and $\mathrm{H}_{2} \mathrm{O}_{2}$ are correlated. In Mars' atmosphere, models including heterogeneous catalysis better reproduce the observed abundance ratios (Encrenaz et al. 2015). In the ISM, because of their common formation pathways on dust grains, $\mathrm{H}_{2} \mathrm{O}$ and $\mathrm{H}_{2} \mathrm{O}_{2}$ are believed to have a common chemical origin. In most of the current astrochemical models (Tielens \& Hagen 1982; Taquet et al. 2012; Du et al. 2012), a value of a few percent for the $\mathrm{H}_{2} \mathrm{O}_{2} / \mathrm{H}_{2} \mathrm{O}$ ratio 
is calculated. This is in line with the upper values of $9 \pm 4 \%$ observed in interstellar ices by Smith et al. (2011).

Though less obvious, the link between $\mathrm{O}_{2}$ and $\mathrm{H}_{2} \mathrm{O}_{2}$ in ISM has also been established by Parise et al. (2014). Both $\mathrm{O}_{2}$ and $\mathrm{H}_{2} \mathrm{O}_{2}$ are overestimated in models and are very elusive to observers, except for the $\rho$ Ophiuchus A core. In this region, dust grains are warm enough to desorb water ice and thus keep a significant fraction of elemental oxygen in the gas phase, with a significant fraction as $\mathrm{O}_{2}$ as stated by Goldsmith et al. (2011). $\rho$ Oph A is also the only region where positive detection of $\mathrm{H}_{2} \mathrm{O}_{2}$ has been done (Bergman et al. 2011). Coincidence or not, the measured $\mathrm{O}_{2} / \mathrm{H}_{2} \mathrm{O}_{2}$ ratios are identical in the ISM and in the coma of $67 \mathrm{P} /$ Churyumov-Gerasimenko. The $\mathrm{H}_{2} \mathrm{O}_{2} / \mathrm{O}_{2}$ ratio is rather low in both cases, with a relative value of $6 \times 10^{-4}$ (Bergman et al. 2011; Bieler et al. 2015).

Our second experiment clearly demonstrates that the desorption of a mixture of $\mathrm{H}_{2} \mathrm{O}_{2} / \mathrm{H}_{2} \mathrm{O}$ at a relative concentration of about $5 \%$ is able to produce $\mathrm{O}_{2}$ and its sudden release into the gas phase at the end of the water desorption. A reasonable initial concentration of $\mathrm{H}_{2} \mathrm{O}_{2}$ of $7 \%$ would give the $3.5 \%$ of $\mathrm{O}_{2}$ detected in the comet. However, if the link between $\mathrm{O}_{2}, \mathrm{H}_{2} \mathrm{O}$ and $\mathrm{H}_{2} \mathrm{O}_{2}$ seems established by our experiments and corroborates the role of the water desorption in the observation of $\mathrm{O}_{2}$, the ratio $\mathrm{H}_{2} \mathrm{O}_{2} / \mathrm{O}_{2}$ of $6 \times 10^{-4}$ observed in astrophysical media is clearly not matched in our experiments. To achieve such a ratio, the dismutation reaction should be almost complete. In our experiments, efficiency is about $50 \%$ for thin films, although the reaction can almost be complete at the very end of water desorption. Loeffler \& Baragiola (2011) have studied the isothermal desorption of $\mathrm{H}_{2} \mathrm{O}_{2} / \mathrm{H}_{2} \mathrm{O}$ mixtures and have demonstrated that the phase separation is obtained at $151.6 \mathrm{~K}$. As a consequence, in our experiments the transportation of $\mathrm{D}_{2} \mathrm{O}_{2}$ (initially on the top of the 25 layers of $\mathrm{H}_{2} \mathrm{O}$ ) through the ASW film during the desorption must take place. Moreover the dissociation of the $\mathrm{D}_{2} \mathrm{O}_{2}: \mathrm{H}_{2} \mathrm{O}$ complex should favour a sudden increase of the $\mathrm{D}_{2} \mathrm{O}_{2}$ concentration close to the sample surface and therefore enhances the dismutation reaction. This is one of the possible explanations for the $\mathrm{O}_{2}$ and $\mathrm{D}_{2} \mathrm{O}$ burst at $155 \mathrm{~K}$, the end of the water desorption.

In our experiments, $\mathrm{H}_{2} \mathrm{O}_{2}$ has two possible evolutions: either it desorbs or it reacts. Obviously, the longer molecules stay on the surface, the higher the temperature increase and therefore, the higher their probability of reacting. In the experiments on silicates, the $\mathrm{H}_{2} \mathrm{O}_{2}$ desorption is not delayed due to the absence of any $\mathrm{H}_{2} \mathrm{O}$ ice cap, and as a consequence the desorption route is maximised and the reaction one minimised. In other words, thin film condition reduces the dismutation reaction efficiency; our experiments correspond to the lower limit of its efficiency (few tens of percent).

Thicker ice layers need more time to sublimate and this increases the interaction time of $\mathrm{H}_{2} \mathrm{O}_{2}$ with itself. If the temperature is increasing (like in our experiments) the desorption temperature is also increased, and therefore the reaction can proceed at higher temperatures. We note that the free desorption of $\mathrm{H}_{2} \mathrm{O}_{2}$ begins at about $150 \mathrm{~K}$ in the first set of experiments, but only at about $155 \mathrm{~K}$ in the second set of experiments. The excess $\mathrm{O}_{2}$ signal can be enhanced by this delayed desorption. At higher temperatures ( $>180 \mathrm{~K}$, inset of Fig. 2), the dismutation is favoured, even if the concentration of $\mathrm{H}_{2} \mathrm{O}_{2}$ is low because of its previous partial desorption. Therefore any effect that would increase the $\mathrm{H}_{2} \mathrm{O}_{2}$ interaction time, or the $\mathrm{H}_{2} \mathrm{O}_{2}$ sublimation temperature (such as a delay by a thick cap of ice) will favour the dismutation reaction. Cometary ices are believed to be of very large thickness. Brown et al. (2012) were able to per- form their experiments at $207 \mathrm{~K}$ by using a meter sized sample and mimicking water sublimation of comets. Even if the detail is beyond the scope of this paper, we add that the total efficiency of two competing mechanisms such as reaction and desorption, both of which follow Arrhenius's laws are very dependent on the heating rate. A fast heating (as in our experiments $10 \mathrm{~K} / \mathrm{min}$ ) favours desorption, whereas a very slow heating (ISM $<\mathrm{K} /$ century, $67 \mathrm{P}$ comet $<0.2 \mathrm{~K} / \mathrm{min}$ ) favours the diffusion, and therefore enhances the reactivity.

Even if the hypothesis of a possible complete dismutation of $\mathrm{H}_{2} \mathrm{O}_{2}$ has still to be explicitly demonstrated by a more complete set of experimental investigations, a transposition to more astrophysically relevant conditions, such as lower heating rate and thicker ice layers would increase our measured high efficiency.

Furthermore our experiments clearly show that some reactions can proceed during the water ice sublimation. Other reactions could also be precursors of molecular oxygen. For example, $\mathrm{OH}+\mathrm{OH}$ has many possible chemical ends, like $\mathrm{O}_{2}+\mathrm{H}_{2}$ or $\mathrm{H}_{2} \mathrm{O}+\mathrm{O}$. The molecules $\mathrm{O}_{2} \mathrm{H}+\mathrm{OH}$ probably react in $\mathrm{O}_{2}+\mathrm{H}_{2} \mathrm{O}$. Therefore, any trapped $\mathrm{O}_{x} \mathrm{H}_{y}$ molecules in water ice, originating from the non total hydrogenation during the water mantle growth, or by later energetic processing (i.e. UV photons, ions ...), have a chance to react during the duration of the desorption of the water. The role of water bulk in reactions between complex molecules is now commonly accepted (Fresneau et al. 2014), even if reactions usually take place before water desorption. As far as the composition of the ice components is a pure dark cloud chemistry (with low UV and few energetic processes), the slow building of the ice should keep the number of such reactive (i.e. $\mathrm{O}_{x} \mathrm{H}_{y}$ ) molecules relatively low. The observed ice composition does not reveal large reservoir of such candidate $\left(<1 \%\right.$ of $\left.\mathrm{H}_{2} \mathrm{O}\right)$. Therefore the contribution of these other molecules to the production of $\mathrm{O}_{2}$ should complement the $\mathrm{H}_{2} \mathrm{O}_{2}$ dismutation but should contribute less.

Comets and asteroids undergo solar winds and light. High energy particles change the chemical composition of the ice, and therefore radicals can be implanted later in ice. But here again, because the major compound of ice is water, the concentration of radicals cannot reasonably be in excess of a few percent of the ice composition. In their paper about ion implantation in water ice, Gomis et al. (2004a,b) have observed hydrogen peroxyde production. The $\mathrm{H}_{2} \mathrm{O}_{2}$ formation rapidly reached the equilibrium between formation and destruction at a value of about 1 to $6 \%$ of the water matrix. Here we note that if water has been processed by solar winds in its solid phase before its desorption in the atmosphere of the comet, the $\mathrm{H}_{2} \mathrm{O}_{2}$ abundance should be in this $1-6 \%$ with respect to the $\mathrm{H}_{2} \mathrm{O}$ range. The dismutation of $\mathrm{H}_{2} \mathrm{O}_{2}$ during ice desorption would also help to understand the low abundance of $\mathrm{H}_{2} \mathrm{O}_{2}$ measured in the comet atmosphere.

Our experiments follow very simply and chronologically a linear temperature ramp. This is not similar to conditions of water sublimation in astrophysical environments. On the surface and in the depth of cometary nuclei, there are huge gradients of temperature, and the desorption of water or other molecules is spatially inhomogeneous and subject to diurnal variation (e.g. Bockelée-Morvan et al. 2015; Lee et al. 2015; Le Roy et al. 2015; Migliorini et al. 2016). Topological and geological diversity makes a comet a very rich but inhomogeneous medium. Furthermore volatile materials can come from below a large cover of dust, and have the possibility to freeze again on the external surface during the comet's night (De Sanctis et al. 2015).

In order to directly apply desorption experiments to comets, we should sum up experiments at all stages of their thermal regimes. Cold deep parts of the comets would correspond to 

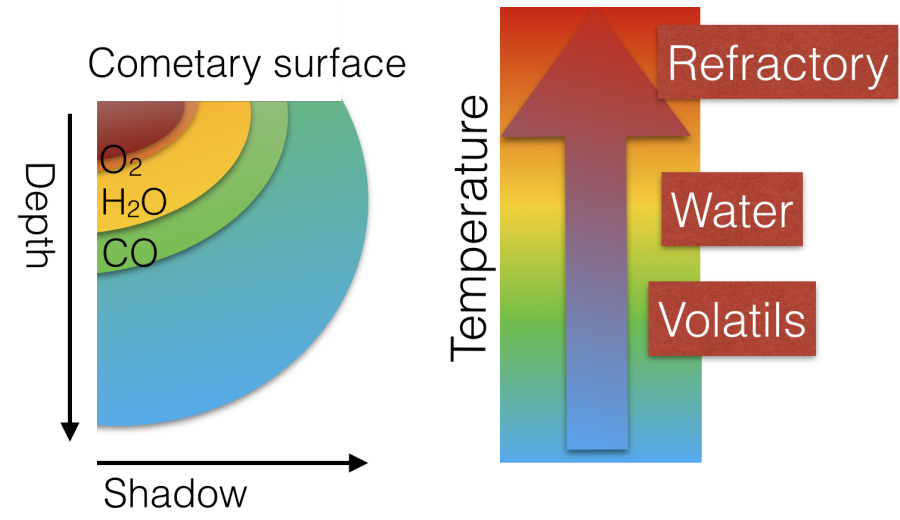

Fig. 4. Simplified schematic view of the gradient of temperature due to the inhomogeneous and time dependent solar illumination. Illustration of the spatially differenced origin of the desorbing molecules.

desorption of high volatility molecules $\left(\mathrm{CO}, \mathrm{N}_{2}\right)$, higher temperature regions would correspond to water desorption, with $\mathrm{O}_{2}$ release due to $\mathrm{H}_{2} \mathrm{O}_{2}$ dismutation occurring at the end of water desorption. Figure 4 illustrates this simple picture of the differentiated origins of molecules desorbing from a comet. Thus, depending on the extension of the water sublimation region, both $\mathrm{H}_{2} \mathrm{O}$ and $\mathrm{O}_{2}$ should be correlated. However, because of their very different temperature of desorption regime, and so because of their different geographical origin, $\mathrm{CO}$ and $\mathrm{N}_{2}$ should follow another time dependency.

\section{Conclusion}

Both in ISM and in comets, the presence of the elusive $\mathrm{O}_{2}$ molecule seems to be linked to $\mathrm{H}_{2} \mathrm{O}$ sublimation. During its formation in prestellar cores, water ice can be incompletely hydrogenated and a fraction of water peroxide, as high as $7 \%$, can be incorporated in the ice mantle. After a long journey, water ice can sublimate from a comet, or from some specific illuminated cores such as $\rho$ Oph A, and its water peroxide component may self-react, being transformed into water and $\mathrm{O}_{2}$, provoking an apparent coincidence of molecular oxygen and water vapor. Our experiments show that the dismutation of $\mathrm{H}_{2} \mathrm{O}_{2}$ before its desorption can be efficient even at very low temperature, although more investigations should be done to demonstrate that it can be complete, to match the observational high ratio of molecular oxygen versus water peroxide.

Acknowledgements. This work was supported by the CNRS program Physique et Chimie du Milieu Interstellaire (PCMI), and the Program DIM-ACAV of the region Ile de France.

\section{References}

Bergman, P., Parise, B., Liseau, R., et al. 2011, A\&A, 531, L8

Bieler, A., Altwegg, K., Balsiger, H., et al. 2015, Nature, 526, 678

Bockelée-Morvan, D., Debout, V., Erard, S., et al. 2015, A\&A, 583, A6

Brown, R. H., Lauretta, D. S., Schmidt, B., \& Moores, J. 2012, Planet. Space Sci., 60,166

Chaabouni, H., Minissale, M., Manicò, G., et al. 2012, J. Chem. Phys., 137, 234706

Collings, M. P., Anderson, M. A., Chen, R., et al. 2004, MNRAS, 354, 1133

Congiu, E., Chaabouni, H., Laffon, C., et al. 2012, J. Chem. Phys., 137, 054713

De Sanctis, M., Capaccioni, F., Ciarniello, M., et al. 2015, Nature, 525, 500

Djouadi, Z., D'Hendecourt, L., Leroux, H., et al. 2005, A\&A, 440, 179

Du, F., Parise, B., \& Bergman, P. 2012, A\&A, 538, A91

Dulieu, F., Amiaud, L., Congiu, E., et al. 2010, A\&A, 512, A30

Encrenaz, T., Greathouse, T. K., Lefèvre, F., et al. 2015, A\&A, 578, A127

Fresneau, A., Danger, G., Rimola, A., et al. 2014, MNRAS, 443, 2991

Giguère, P. A., \& Secco, E. A. 1954, Can. J. Chem., 32, 550

Goldsmith, P. F., Liseau, R., Bell, T. A., et al. 2011, ApJ, 737, 96

Gomis, O., Leto, G., \& Strazzulla, G. 2004a, A\&A, 420, 405

Gomis, O., Satorre, M., Strazzulla, G., \& Leto, G. 2004b, Planet. Space Sci., 52, 371

Hall, D. T., Strobel, D. F., Feldman, P. D., McGrath, M. A., \& Weaver, H. A. 1995, Nature, 373, 677

Hincelin, U., Wakelam, V., Hersant, F., et al. 2011, A\&A, 530, A61

Ioppolo, S., Cuppen, H. M., Romanzin, C., van Dishoeck, E. F., \& Linnartz, H. 2008, ApJ, 686, 1474

Ioppolo, S., Cuppen, H. M., Romanzin, C., van Dishoeck, E. F., \& Linnartz, H. 2010, Phys. Chem. Chem. Phys., 12, 12065

Jing, D., He, J., Brucato, J., et al. 2011, ApJ, 741, L9

Johnson, R., Luhmann, J., Tokar, R., et al. 2006, Icarus, 180, 393

Kanekar, N., \& Meier, D. S. 2015, ApJ, 811, L23

Lamberts, T., de Vries, X., \& Cuppen, H. M. 2014, Faraday Discussion, 168, 327

Larsson, B., Liseau, R., Pagani, L., et al. 2007, A\&A, 466, 999

Le Roy, L., Altwegg, K., Balsigerand, H., et al. 2015, A\&A, 583, A1

Lee, S., von Allmen, P., Allen, M., et al. 2015, A\&A, 583, A5

Liseau, R., Goldsmith, P. F., Larsson, B., et al. 2012, A\&A, 541, A73

Loeffler, M. J., \& Baragiola, R. A. 2011, J. Phys. Chem. A, 115, 5324

Loeffler, M. J., Teolis, B. D., \& Baragiola, R. A. 2006, J. Chem. Phys., 124, 104702

Melnick, G. J., \& Kaufman, M. J. 2015, ApJ, 806, 227

Migliorini, A., Piccioni, G., Capaccioni, F., et al. 2016, A\&A, 589, A45

Miyauchi, N., Hidaka, H., Chigai, T., et al. 2008, Chem. Phys. Lett., 456, 27

Mokrane, H., Chaabouni, H., Accolla, M., et al. 2009, ApJ, 705, L195

Noble, J. A., Theule, P., Mispelaer, F., et al. 2012, A\&A, 543, A5

Noble, J. A., Diana, S., \& Dulieu, F. 2015, MNRAS, 454, 2636

Oba, Y., Miyauchi, N., Hidaka, H., et al. 2009, ApJ, 701, 464

Oba, Y., Watanabe, N., Hama, T., et al. 2012, ApJ, 749, 67

Oba, Y., Osaka, K., Watanabe, N., Chigai, T., \& Kouchi, A. 2014, Faraday Discussion, 168, 185

Parise, B., Bergman, P., \& Menten, K. 2014, Faraday Discussion, 168, 349

Romanzin, C., Ioppolo, S., Cuppen, H. M., van Dishoeck, E. F., \& Linnartz, H. 2011, J. Chem. Phys., 134, 084504

Rubin, M., Altwegg, K., Balsiger, H., et al. 2015, Science, 348, 232

Scott Smith, R., Huang, C., \& Kay, B. D. 1997, J. Chem. Phys. B, 101, 6123

Smith, R. G., Charnley, S. B., Pendleton, Y. J., et al. 2011, ApJ, 743, 131

Taquet, V., Ceccarelli, C., \& Kahane, C. 2012, A\&A, 538, A42

Tielens, A. G. G. M., \& Hagen, W. 1982, A\&A, 114, 245

Westley, M. S., Baragiola, R. A., Johnson, R. E., \& Baratta, G. A. 1995, Nature, 373, 405

Yildiz, U. A., Acharyya, K., Goldsmith, P. F., et al. 2013, A\&A, 558, A58 